\title{
RESEARCH ON NUMERICAL SIMULATION OF FORMING PROCESS FOR SINGLE SCREW EXTRUDER
}

\author{
Gou Yanan ${ }^{1}$,Zhao Peng ${ }^{1,2}$, Ning Tingzhou $^{1^{*}}$ \\ ${ }^{1}$ College of Mechanical and Electrical Engineering, Zaozhuang University, Zaozhuang 277160, China \\ ${ }^{2}$ School of Mechanical Engineering, University of Jinan, Jinan 250022, China \\ E-mail: ning-tingzhou@163.com
}

\begin{abstract}
Polymer materials have been widely used in various fields of national economy, such as medical treatment, transportation, agriculture, industry, etc. In engineering, most plastic products are processed by extrusion molding, and the single screw extruder is an important processing tool. This article takes the single screw extruder widely used in plastic production as the research object. Based on the Flow Simulation fluid dynamics analysis function in SolidWorks software, the simulation study of its molding process was carried out, and the temperature field, pressure field and velocity field of the fluid inside the extruder were obtained, which could provide theoretical basis and guidance for the design and processing technology of single screw extrusion molding equipment.
\end{abstract}

Keywords: Single screw extruder; Molding process; Numerical simulation; Fluid dynamics.

\section{Introduction}

China is a big country in the application of polymer materials[1], which is involved in all areas of life. Among the methods of processing materials, the extruder is the most widely used[2], and its extrusion molding processing technology can produce the required products with high efficiency and large output. Driven by demand, related technologies in China are also developing rapidly. Around 2010, plastic production was 58.38 million tons. In recent years, the output can reach about 80 million tons. However, compared with foreign highprecision equipment, Chinese extruders still have some shortcomings, and the phenomenon of dependence on imports still exists. Therefore, it is of great significance to produce an extruder that meets the needs of Chinese production, which will greatly reduce production costs.

The researchers systematically studied the screw extruder based on numerical simulation, and put forward a relatively complete mathematical model and many innovative ideas. For example, Liu Weiliang established a three-dimensional flow model of a single screw mixing unit for non-Newtonian isothermal viscous fluid[3]. Ma Dejun and Chen Jinnan established a three-dimensional nonNewtonian isothermal viscous fluid plasticization process model with or without threads in the head of an injection molding machine[4]. Dong Zhonghua, Jiang Bo and Guo Jian established a threedimensional non-Newtonian non-isothermal viscous fluid flow and mixing model in a co-rotating twinscrew extruder[5]. Dong Zhonghua, Jiang Bo and Xu Shuhua established a three-dimensional nonNewtonian non-isothermal viscous fluid flow model in a co-rotating twin-screw extruder[6].

This article takes the single screw extruder widely used in plastic production as the research object. Based on the Flow Simulation fluid dynamics analysis function in SolidWorks software, the simulation study of its molding process was carried out, and the temperature field, pressure field and velocity field of the fluid inside the extruder were obtained, which could provide theoretical basis and guidance for the design and processing technology of single screw extrusion molding equipment.

\section{Structure and Working Principle of Single Screw Extruder}

\subsection{Structure of Single Screw Extruder}

Transmission system, heating system and extrusion system are the three elements of single screw extruder[7], as shown in Figure 1.

The transmission system is to drive the screw to work, which is mainly composed of a motor, a belt 
drive, a reducer, etc, the extrusion system is composed of a screw, a barrel, etc, and the heating system is to make the material reach the plasticizing temperature, which is mainly composed of electromagnetic heaters. The details are shown in Figure

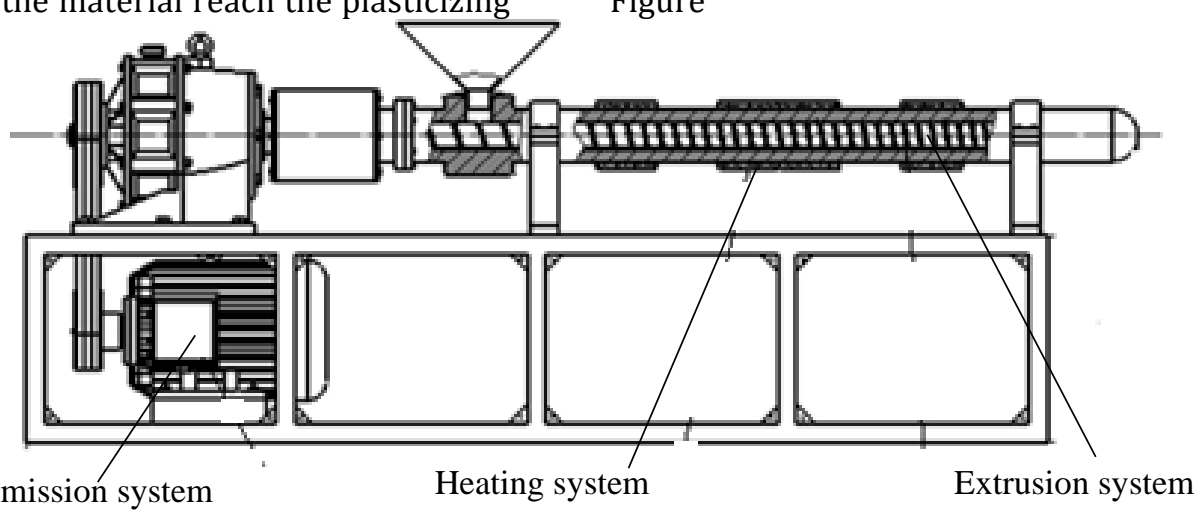

Figure 1: Plan view of single screw extruder

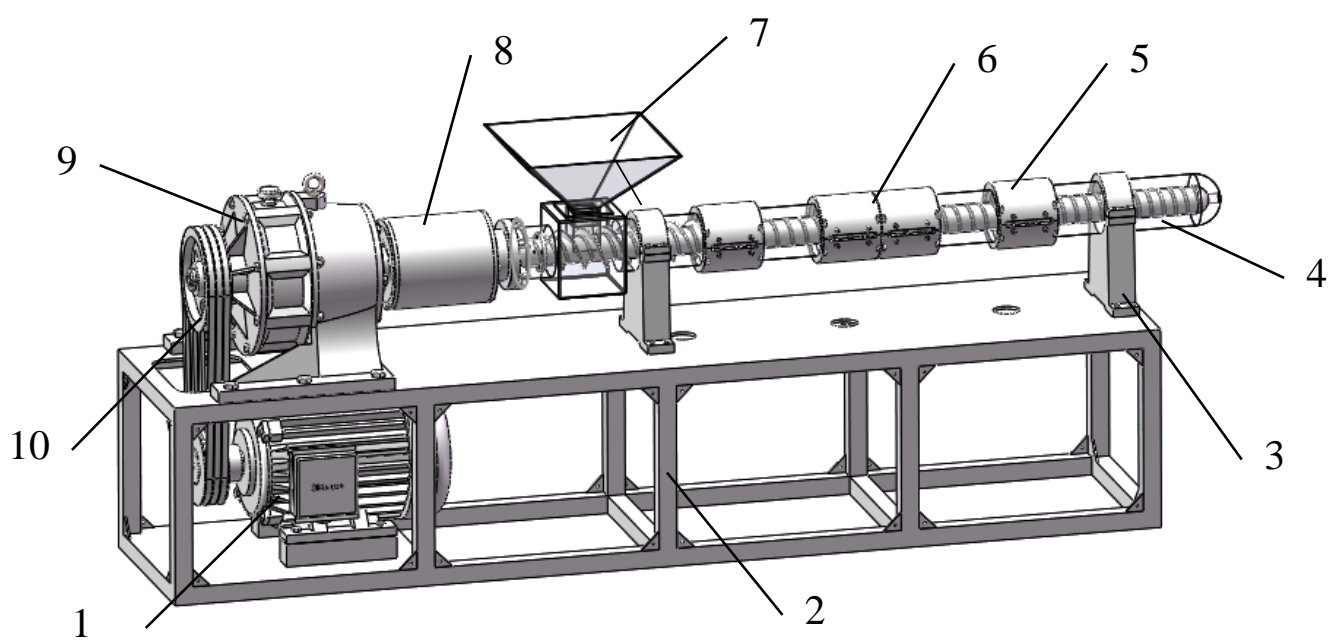

1.Motor; 2.Frame; 3.Support frame; 4.Barrel; 5.Screw; 6.Electromagnetic heater; 7.Hopper; 8.Coupling; 9.Cycloid reducer; $10 . \mathrm{V}$ belt drive

Figure 2: Three-dimensional view of single screw extruder

\subsection{Working Principle of Single Screw Extruder}

The power is transmitted from the motor to the cycloid reducer through the V-belt, and then the cycloid reducer drives the screw to rotate through the coupling. At this time, the material enters the barrel from the hopper. Firstly, enters the conveying section of the screw, secondly, enter the compression section, thirdly, enter the metering section, and finally squeeze out from the head evenly.

The single screw extruder is generally divided into three sections, each section accounting for about one third, they are the conveying section, compression section and metering section[8], as shown in Figure 3 . In the first section of the conveying section, the material enters, preheats and compacts. It is transported to the second compression section through the movement of the screw, where the material will be heated and begin to plasticize, and then transported to the third metering section through the movement of the screw, the melted material will be melt more completely because of the further increase in pressure, and at this time the material will be quantitatively transported to the position of the machine head and the plastic will be extruded.

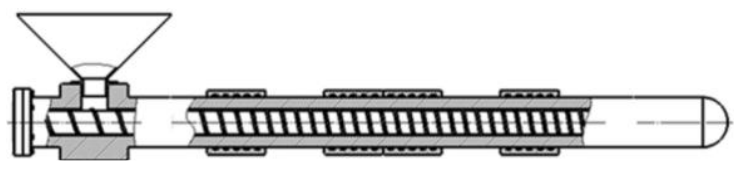

Conveying section Compression section Metering section

Figure 3: Segmentation of single screw extruder 


\section{Simulation of Single Screw Extruder Molding Process}

\subsection{Preparation Before Solution}

\subsubsection{Determination of the unit}

In order to facilitate calculation and observation, standard international units are used in this design. Length unit: mm, mass unit: g, time unit: s, pressure unit: MPa.

\subsubsection{Analysis type}

The analysis type selects internal and heat conduction in solids. The reference axis is the axis of the screw ( $\mathrm{Z}$ axis), as shown in Figure 4.

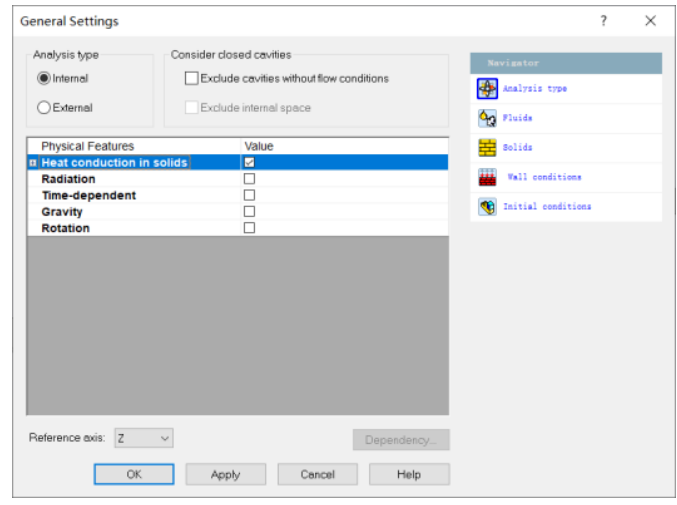

Figure 4: Analysis type

\subsubsection{Setting of fluid and solid}

The fluid used in this study is PVC (polyvinyl chloride), and the selected material of the barrel and its screw is 45 steel, the fluid and solid settings are shown in Figure 5.

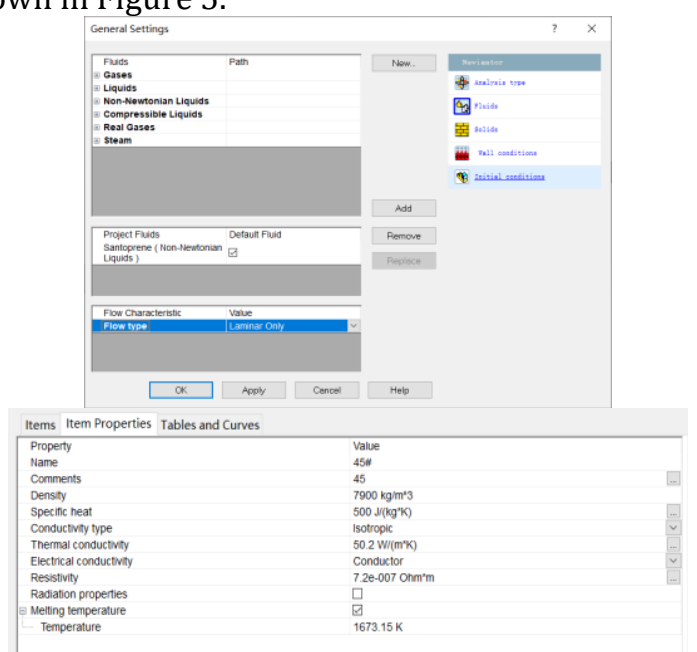

Figure 5: Settings of fluid and solid

\subsection{Determination of Boundary Conditions}

\subsubsection{Boundary conditions}

SolidWorks Flow Simulation can set multiple boundary conditions, the inlet volume flow, inlet velocity, outlet volume flow, outlet velocity and various pressures inlet and outlet, wall conditions.
Since PVC (polyvinyl chloride) starts to change to viscous flow at $180^{\circ} \mathrm{C}$, this simulation sets the barrel temperature to $180^{\circ} \mathrm{C}$. Since the movement of the screw is a rotary movement, the rotation speed of the screw is selected as $50 \mathrm{r} / \mathrm{min}$ in this simulation, so the rotation speed of $5 \mathrm{rad} / \mathrm{s}$ is added to the inner wall of the screw. Add an inlet pressure of $2.0 \mathrm{MPa}$ at the inlet, an atmospheric pressure of $0.1 \mathrm{MPa}$ at the outlet, and an external temperature of $20^{\circ} \mathrm{C}$. The specific boundary conditions can be seen in Table 1 .

Table 1 Setting of boundary conditions

\begin{tabular}{|c|c|c|}
\hline Items & $\begin{array}{c}\text { Thermal boundary } \\
\text { conditions }\end{array}$ & $\begin{array}{c}\text { Flow boundary } \\
\text { conditions }\end{array}$ \\
\hline Barrel & $180^{\circ} \mathrm{C}$ & fixed \\
\hline Screw & & $5 \mathrm{rad} / \mathrm{s}$ \\
\hline Inlet & $180^{\circ} \mathrm{C}$ & $2.0 \mathrm{MPa}$ \\
\hline Outlet & $20^{\circ} \mathrm{C}$ & $0.1 \mathrm{MPa}$ \\
\hline
\end{tabular}

\subsubsection{Screw parameters}

The main structural parameters of the screw are shown in Table 2.

Table 2 Main structural parameters of screw

\begin{tabular}{|c|c|c|c|c|}
\hline $\begin{array}{c}\text { Screw } \\
\text { speed }\end{array}$ & $\begin{array}{c}\text { Screw } \\
\text { length }\end{array}$ & $\begin{array}{c}\text { Thread } \\
\text { width }\end{array}$ & $\begin{array}{c}\text { Groove } \\
\text { depth }\end{array}$ & $\begin{array}{c}\text { Screw } \\
\text { diameter }\end{array}$ \\
\hline $5 \mathrm{rad} / \mathrm{s}$ & $2250 \mathrm{~mm}$ & $9 \mathrm{~mm}$ & $4.5 \mathrm{~mm}$ & $90 \mathrm{~mm}$ \\
\hline
\end{tabular}

\subsection{Grid Division}

SolidWorks Flow Simulation can automatically generate grids. In this study, the gap between the barrel and the screw is $0.45 \mathrm{~mm}$, the groove depth is $4.5 \mathrm{~mm}$, and the gap is too small, so the gap should be manually set, so the mesh refinement level at the fluid boundary is manually adjust to a higher level 4 . The total number of grids reached 46,298 , and the number of fluid grids reached 15,481. Part of the grid division diagram is shown in Figure 6, and the grid division data is shown in Figure 7.

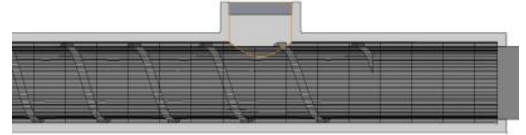

Figure 6: Part of the grid division diagram

$\begin{array}{ll}\text { Parameter } & \text { Value } \\ \text { Status } & \text { Mesh generation finished normally. } \\ \text { Total cells } & 1,601,160 \\ \text { Fluid cells } & 625,275 \\ \text { Solid cells } & 975,885 \\ \begin{array}{l}\text { Fluid cells contacting solids } \\ \text { Cpu time }\end{array} & 495,629 \\ \text { Calculation time left } & 0: 2: 55 \\ \text { Run at } & \text { LAPTOP-MNB3J9E1 }\end{array}$

\begin{tabular}{ll}
\hline Warning & Comment \\
No warnings &
\end{tabular}

Figure 7: Grid division data 


\subsection{Model Check}

\subsubsection{Interference check}

Select the Check to perform interference inspection, the result is shown in Figure 8.

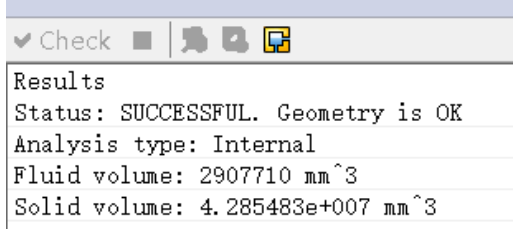

Figure 8: Interference check

\subsubsection{Fluid check}

Check the fluid area, everything is normal, the result is shown in Figure 9.

Figure 9: Fluid area

\subsection{Wall Setting}

The screw is selected as the real wall, the rotation speed is $5 \mathrm{rad} / \mathrm{s}$, and the temperature is $20^{\circ} \mathrm{C}$. The surface of the barrel is selected as the real wall surface, and the heating temperature is $180^{\circ} \mathrm{C}$. The specific parameters are shown in Figure 10.

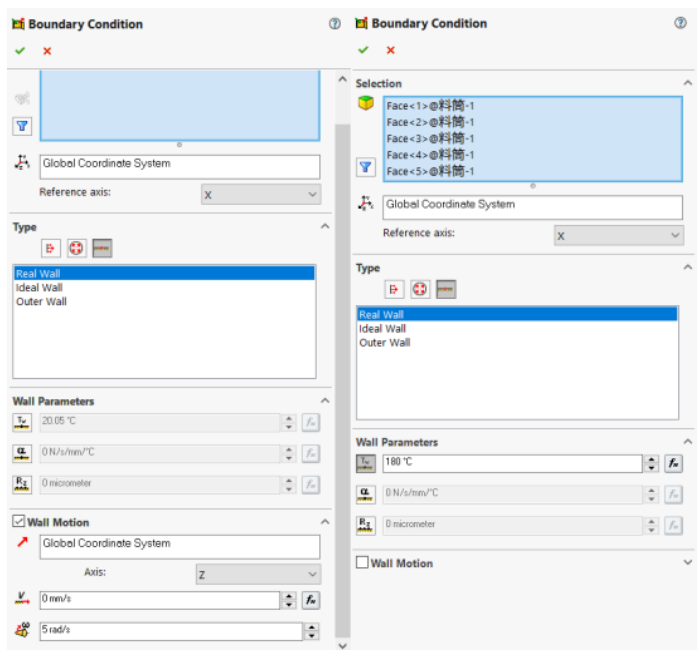

Figure 10: Wall setting

\section{Results}

\subsection{Flow Trace}

Figure 11 is the diagram showing fluid traces inside the barrel.

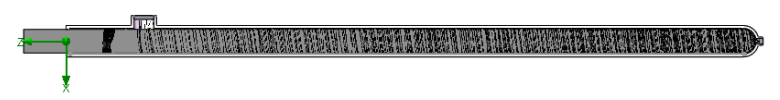

Figure 11: Display of fluid traces inside the barrel

It can be clearly seen from Figure 11 that the fluid flow is relatively stable and uniform, and the fluid basically flows along the designed spiral groove, and the motion is a uniform rotary motion.

\subsection{Temperature Field}

(1) Solid temperature distribution diagram of extruder

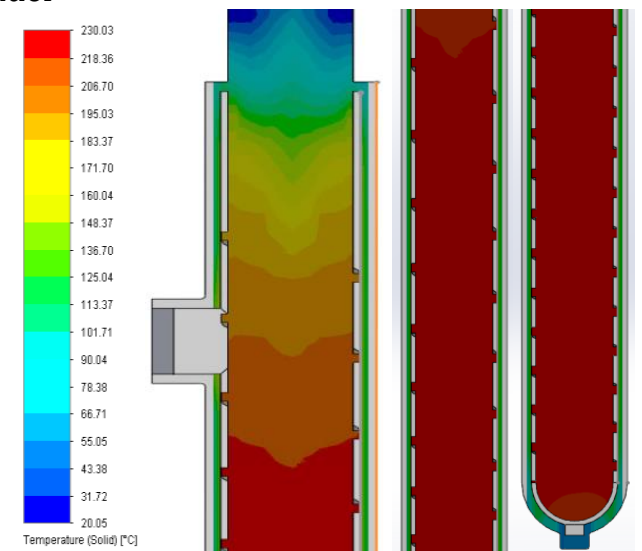

Figure 12: Solid temperature distribution diagram of extruder

The result can be obtained from Figure 12, when the fluid just enters the barrel, the solid temperature reaches $190^{\circ} \mathrm{C}$ due to the heating of the barrel. On the contrary, the temperature of the exposed part of the screw drops rapidly to $20^{\circ} \mathrm{C}$. As the fluid flows from the conveying section into the compression section, the temperature gradually reaches $230^{\circ} \mathrm{C}$, which is the result of the combined action of the rotary motion of the screw and the heating of the barrel.

(2) Fluid temperature distribution diagram

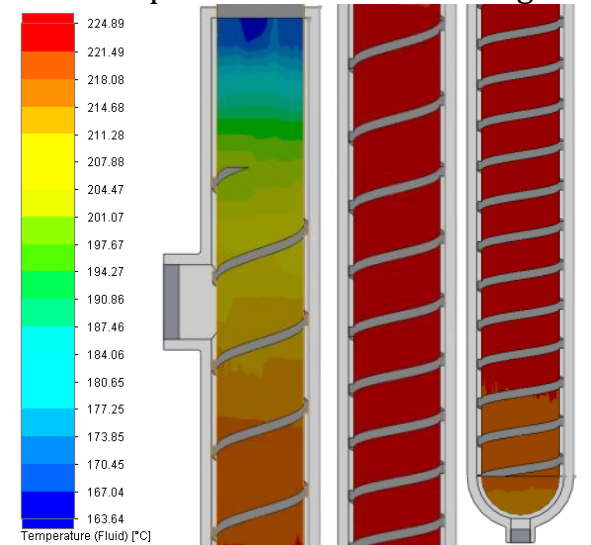

Figure 13: Fluid temperature distribution diagram

(3) XY line chart of fluid temperature

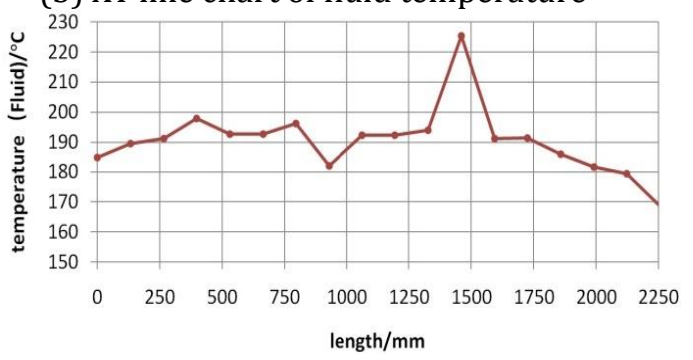

Figure 14: XY line chart of fluid temperature 
It can be concluded from Figure 13 and Figure 14 that when the fluid just enters the barrel, the fluid temperature can reach $185^{\circ} \mathrm{C}$ due to the heating of the barrel. As the screw rotates and the barrel is heated, as the fluid flows from the conveying section into the compression section, the temperature gradually rises, reaching above $190^{\circ} \mathrm{C}$, and the polyvinyl chloride has been heated to its melting point. Since the length of the compression section is also $750 \mathrm{~mm}$, the temperature gradually rises at $1250 \mathrm{~mm}$ and reaches the peak of $225^{\circ} \mathrm{C}$ at $1500 \mathrm{~mm}$ (just after the compression section), and then the fluid temperature gradually decreases to about $170^{\circ} \mathrm{C}$ due to the lower indoor temperature near the outlet.

\subsection{Pressure Field}

(1) Surface pressure distribution diagram of screw
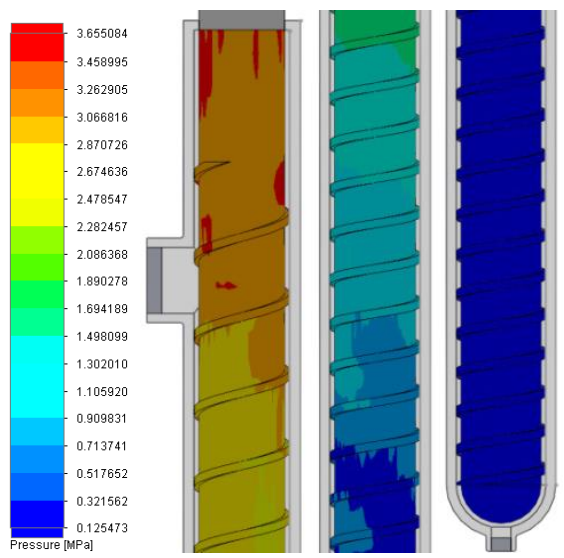

Figure 15: Surface pressure distribution diagram of screw

(2) XY line chart of static pressure

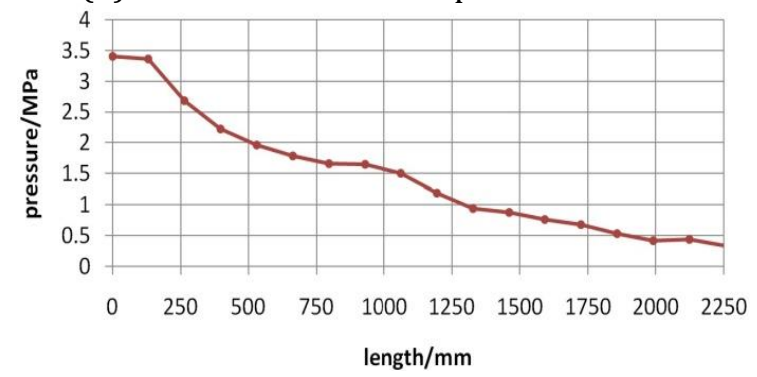

Figure 16: XY line chart of static pressure

From Figure 15 and Figure 16, it can be seen that the fluid can reach 3.4 MPa when it just enters. With the rotation of the screw, when the fluid enters the compression section from the conveying section, the pressure decreases to about 1.7 MPa. When the fluid enters the metering section from the compression section, it gradually decreases to $0.6 \mathrm{MPa}$, and finally closes to the atmospheric pressure of $0.3 \mathrm{MPa}$ at the outlet.

\subsection{Velocity Field}

(1) Fluid velocity distribution diagram

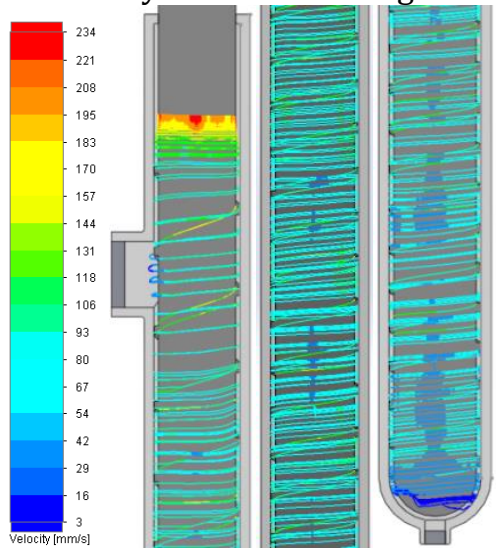

Figure 17: Fluid velocity distribution diagram

(2) XY line chart of velocity

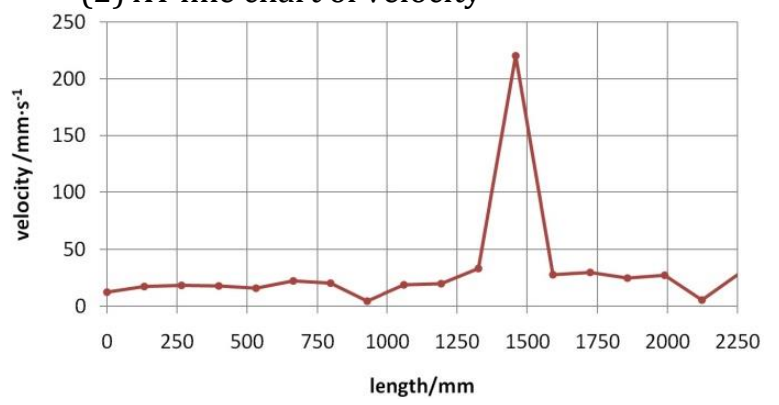

Figure 18: XY line chart of velocity

It can be seen from Figure 17 and Figure 18 that the fluid flow inside the barrel is more complicated and the speed is not stable.

The velocity in the conveying section of inlet is low, and can reach the speed of about $20 \mathrm{~mm} / \mathrm{s}$. Due to the rotation of the screw and the punching of the fluid, at the $1250 \mathrm{~mm}$ position, when the fluid gradually flows from the compression section into the metering section, the speed gradually increases, reaching the peak of about $220 \mathrm{~mm} / \mathrm{s}$ at $1500 \mathrm{~mm}$. Then the speed drops to $30 \mathrm{~mm} / \mathrm{s}$, and gradually stabilizes, and the fluid is output from the screw head steadily.

\section{Conclusions}

Taking the single screw extruder widely used in plastic production as the research object, the forming process of it was simulated and studied based on SolidWorks Flow Simulation, and the temperature field, pressure field and velocity field of the fluid inside the extruder were obtained. The relevant conclusions could provide theoretical basis and guidance for the design and processing technology of the single screw extruder. 


\section{Acknowledgements}

This work was supported by Zaozhuang Science and Technology Plan Project (2019GX10) and Zaozhuang University Doctoral Research Startup Fund Project (2018BS030).

\section{References}

[1] Cui Yijie, Song Shengju, Qu Xiaozhong, Huang Jijun.(2017). Rethinking and Outlook on the Development of Polymeric Materials Industry under the View of "Made in China 2025".Journal of Engineering Studies,9(6): 568-576.

[2] Gao Gang.(2015).Study on the structure optimization and mixing properties of barrier mixers of single screw extruder. Shanghai: East China University of Science and Technology.

[3] Liu Weiliang.(2006).The Simulation and Analysis of The Flow of Screw Mixier.Beijing: Beijing University of Chemical Technology.
[4] MA Dejun, CHEN Jinnan.(2006). Simulations of Three-Dimensional Flow Fields in Metering Section of Screw During Plasticization Process. Journal of Petrochemical Universities, 19(2):5054.

[5] DONG Zhong-hua, JIANG Bo, GUO Jian. (2005).Varied flow and blended simulation of guiding screw thread component in the same direction twin screw extruder. China Rubber/Plastics Technology and Equipment, (7):1-5.

[6] DONG Zhong-hua, JIANG Bo, XU Shu-hua.(2005). Flow and Mixing Simulation for Turbine Mixing Elements in A Co-rotating Twin Screw Extruder. China Plastics,19(2):90-94.

[7] GUO Lin, REN Juan, GU Kang.(2018).SJS90 Single-screw Extruder Based on PLC and Inverter Control. Modern Manufacturing Technology and Equipment, (9):167-169.

[8] LI Ming-hui, YANG Xing-kui.(2018,). Temperature Control Strategy for Injection Modeling Machine Barrel Based on Internal Model Decoupling. Packaging Engineering, 39(5):141-145. 